\title{
Polychlorinated biphenyls in the drinking water source of the Yangtze River: characteristics and risk assessment
}

\author{
Xiaoai Cui ${ }^{1,2}$, Jing Dong ${ }^{1}$, Zhifeng Huang ${ }^{1}$, Chengyou Liu ${ }^{1}$, Xiaocui Qiao ${ }^{1}$, Xing Wang ${ }^{1}$, Xingru Zhao ${ }^{1 *}$, \\ Binghui Zheng ${ }^{1 *}$ (D) and Jinshan Shen ${ }^{2}$
}

\begin{abstract}
Background: As the longest river in Asia, the Yangtze River flows through the most industrialized cities in China and provides critical ecological services for agriculture, industry, and transportation. Polychlorinated biphenyls (PCBs) have been banned for many years, but trace amounts of PCBs still exist as persistent organic pollutant in drinking water and are an ecotoxicological problem. In this work, we collected water, sediment, and suspended particulate matter (SPM) samples along the Yangtze River, to study the distribution and transport of PCBs for the risk assessment of the Yangtze River as a drinking water source.

Results: The $\Sigma P C B s$ concentrations in water, sediment, and SPM ranged in 0.04-11 ng/L, 0.33-69 ng/g, and $0.72-$ $153 \mathrm{ng} / \mathrm{L}$, respectively. The main pollutants were PCB17, 18, 28, 47, and 118 in the Yangtze River. The $\mathrm{ff}_{S W}$ value of PCB18 and PCB28 all exceeded 0.50, whereas the $\mathrm{ff}_{\text {SW }}$ value of PCB47 and PCB1 18 (except for PCB1 18 at Y-4) was less than 0.50 . The toxic equivalent quantity (TEQ) range of PCBs in water and in sediment was ND-5.55 pg-TEQ/L and ND-2.51 pg-TEQ/g, respectively.

Conclusions: In both water and sediment, lower chlorinated PCBs are dominant in the middle reaches and higher chlorinated PCBs are dominant at downstream. In contrast, SPM is dominated by tetra-CBs. The $\mathrm{ff}_{S W}$ values reveal a net redissolution of lower PCBs from sediments to water but a net sorption of higher PCBs from water to sediment. The PCBs in water and sediment at downstream pose potential ecological risk, but the drinking water does not have a non-carcinogenic risk for humans.
\end{abstract}

Keywords: Polychlorinated biphenyls (PCBs), Yangtze River, Risk assessment, Drinking water source

\section{Background}

As the longest river in Asia, the Yangtze River supports the livelihood of $>400$ million inhabitants and flows through a basin of about $1.8 \times 10^{6} \mathrm{~km}^{2}$ in size [1], covering regions with the highest level of urbanization and industrialization in eastern China that contribute to

\footnotetext{
*Correspondence: zhaoxr@craes.org.cn; zhengbinghui@craes.org.cn

${ }^{1}$ National Engineering Laboratory for Lake Pollution Control

and Ecological Restoration, State Environmental Protection Key Laboratory of Drinking Water Source Protection, Chinese Research

Academy of Environmental Sciences, Beijing 100012, China

Full list of author information is available at the end of the article
}

about $42 \%$ of China's Gross Domestic Product [2]. It is an important freshwater resource in China and provides numerous ecological services for agriculture, industry, and transportation. The lower reaches of the Yangtze River provide $80-100 \%$ of the drinking water for economically developed and densely populated regions like Jiangsu and Shanghai [3, 4], but water quality has been menaced in recent years by rapid industrialization and accelerated urbanization.

Polychlorinated biphenyls (PCBs) include 209 congeners whose physicochemical properties and toxicity depend on the number and position of chlorine atoms in the molecule [5]. Because of their chemical stability and 
heat resistance, PCBs were once widely used as additives in heat exchange fluids, components for transformers and large capacitors, carbon-free copy paper, as well as paints and plastics, before their persistence and toxicity were examined and revealed [6-8]. In general, PCB28, 52, $101,118,138,153$, and 180 are indicative polychlorinated biphenyls (ind-PCBs) and are often used as indicators of environmental pollution [9], whereas coplanar polychlorinated biphenyls (co-PCBs) including PCB77, 81, 105, $114,118,123,126,156,157,167,169$, and 189 are used to estimate the toxicity of PCBs $[10,11]$. The PCBs ubiquitous in the environment are notorious for their bioaccumulation and ability to transport over long distance [12]. Upon entering the water environment, PCBs are adsorbed by particulate matter because they are insoluble in water and eventually precipitate in the sediment [13]. However, sediment can resuspend when environmental factors change (e.g., turbulence caused by ship motion or flooding), and adsorbed PCBs are then released back into the water to start another cycle of environmental contamination $[14,15]$ and eventually accumulate in organisms. In fact, the transport of PCBs along the food web poses a serious risk to ecological integrity and human health $[16,17]$. Therefore, it is of great importance to understand the transport of PCBs in water, sediment, and suspended particulate matter (SPM) to evaluate their risks in drinking water source.
Some studies have reported on the occurrence and distribution of PCBs in the source water and sediment of the Yangtze River [18-20], but the transport of PCBs along the Yangtze River in water, sediment, and SPM remains overlooked. In this work, we calculated the fugacity fraction of PCBs in sediment based on the PCBs concentrations determined by isotope dilution HRGC/HRMS, to evaluate the sediment-water diffusion of PCBs and their risk in the drinking water source of the Yangtze River.

\section{Materials and methods \\ Study area}

The samples originated from the middle and lower reaches of the Yangtze River. The collection area passes through Hubei, Anhui, Jiangxi, and Jiangsu provinces, and covers the entire middle and lower reaches of the Yangtze River. Samples were collected in November 2016 from drinking water sources along the Yangtze River at specified sites (Fig. 1). Overlying water was first filled into 1-L brown glass bottles, stored in ice box, then brought back to the laboratory and passed through a $0.45-\mu \mathrm{m}$ filter membrane to get the water sample and the SPM sample. Sediment was collected from the surface of the riverbed, wrapped in aluminum foil, and sealed in polythene bag, then freeze-dried and frozen at $-20{ }^{\circ} \mathrm{C}$ until chemical analysis. To reduce possible random variation during collection, at least three replicates were collected

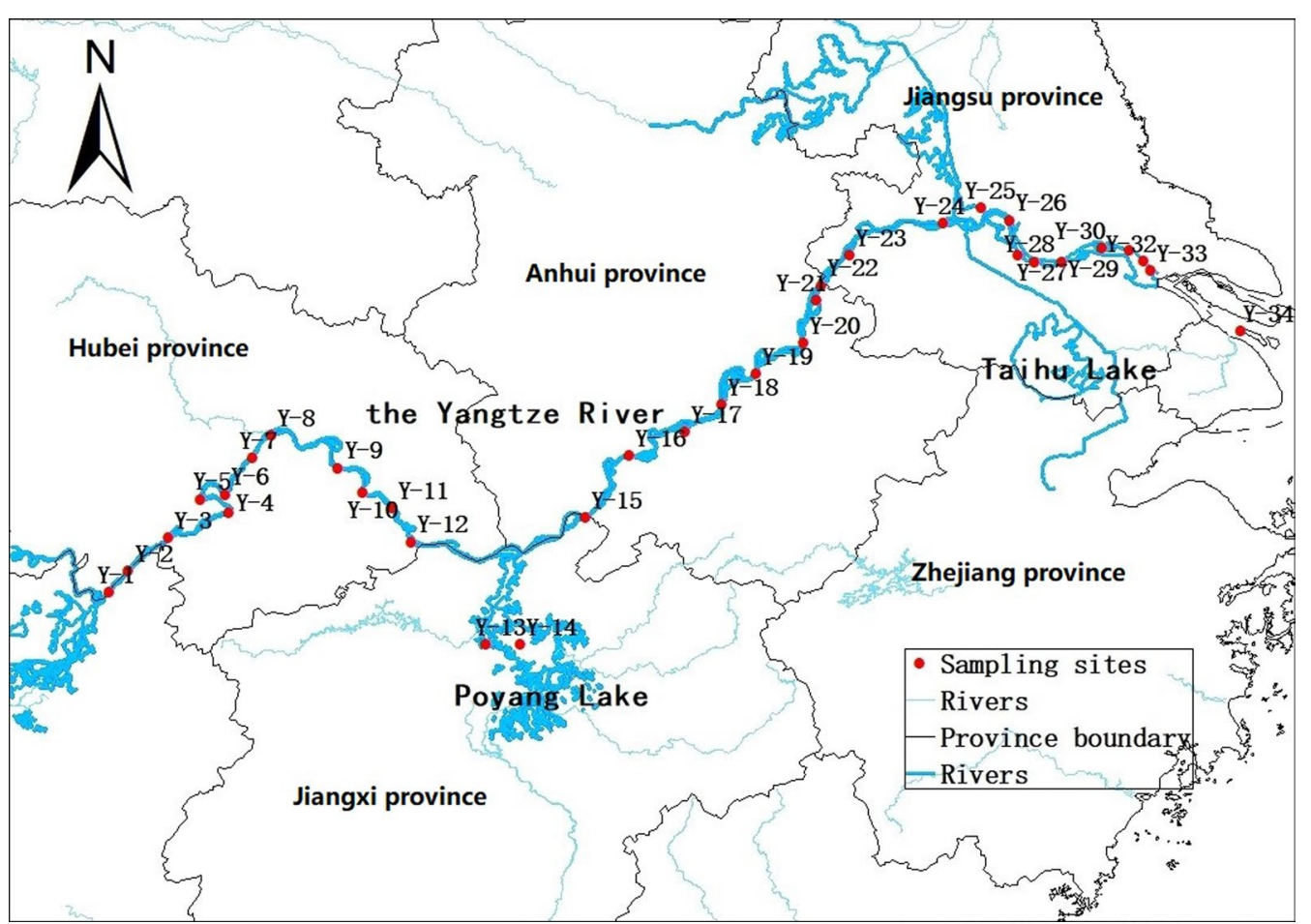

Fig. 1 Sampling sites along the Yangtze River 
at each site for both overlying water and sediment, and the eventual sample of the site was a composite of all replicates after thorough mixing.

\section{Chemicals and materials}

All solvents were of pesticide residue grade and purchased from Fisher (Fair Lawn, NJ, USA) and Tedia (Fairfield, OH, USA). The standard solutions EC-4977 (method 1668A toxics/LOC/window defining) and EC-4979 (method 1668A injection internal standard solution) were supplied by Cambridge Isotope Laboratories (Andover, MA, USA).

Anhydrous sodium sulfate, silver nitrate and sodium hydroxide were of analytical grade and purchased from Beijing Chemical Factory (Beijing, China). Silica gel (100-200 mesh) was purchased from Qingdao Haiyang Chemical Co., Ltd. (Shandong, China). Basic aluminum oxide (100-200 mesh) was purchased from Sinopharm Chemical Reagent Co., Ltd. (Shanghai, China).

\section{Analytical method}

Water samples were spiked with the EC-4977 standard ( $1 \mathrm{ng}$ ) and equilibrated for at least $2 \mathrm{~h}$ prior to solid phase extraction. Samples of sediment and suspended particle matter were pretreated according to the methods of Zhao et al. [21]. That is, the solid sample (about $2 \mathrm{~g}$ ) was spiked with $1 \mathrm{ng}$ of ${ }^{13} \mathrm{C}$-labeled EC-4977 and homogenized with sodium sulfate $(10 \mathrm{~g})$ with mortar and pestle. The homogenized mixture was allowed to equilibrate for at least $12 \mathrm{~h}$ before accelerated solvent extraction (ASE) was carried out. The extracts were cleaned up, and passed through multi-layer silica gel and basic aluminum oxide, and the recovered compounds were finally identified and quantified with a DB-5MS column $(60 \mathrm{~m} \times 0.25 \mathrm{~mm} \times 0.25 \mu \mathrm{m})$ by isotope dilution HRGC/HRMS. In this paper, 209 congeners of PCBs are analyzed.

\section{Quality control and quality assurance (QA/QC)}

The laboratories must show its ability to generate acceptable method blank, precision, and recovery. Initial precision and recovery tests were performed according to Zhao et al. [21], including sample preparation, extraction, and clean-up. The limit of detection was defined as the level of $\mathrm{S} / \mathrm{N}=3: 1$ in the measurement of spiked samples. The limit of detection for PCBs ranged in $0.3-1.8 \mathrm{pg} / \mathrm{L}$ for water, and $0.9-6.5 \mathrm{pg} / \mathrm{g}$ for sediment (dry weight). The recoveries of PCBs spiked in water and sediment samples ranged in $58-80 \%$ and $70-98 \%$, respectively, and the relative standard deviation (RSD) was less than $20 \%$.

\section{Data and statistical analyses}

The SPM water partition coefficient $K_{\mathrm{d}}(\mathrm{kg}$ SPM per L water) was calculated as follows [22]:

$$
K_{\mathrm{d}}=C_{\mathrm{M}} / C_{\mathrm{W}}
$$

where $C_{\mathrm{M}}(\mathrm{mg} \mathrm{PCBs} / \mathrm{L} \mathrm{SPM})$ and $C_{\mathrm{W}}(\mathrm{mg} \mathrm{PCBs} / \mathrm{L}$ water $)$ are the concentrations of $\mathrm{PCBs}$ in the aqueous and solid phases, respectively.

The normalized partition coefficient of organic carbon $\left(K_{\mathrm{OC}}\right)$ is an empirical value of the steady-state environment simulated in the laboratory and can be predicted by $K_{\text {OW }}$ ( $n$-octanol/water partition coefficient) [23]:

$$
\log K_{\mathrm{OC}}=1.04 \log K_{\mathrm{OW}}-0.61
$$

$K_{\mathrm{OC}}{ }^{*}$ is the modified normalized partition coefficient of organic carbon found in the field and can be calculated as [24]:

$$
K_{\mathrm{OC}} *=\left(C_{\mathrm{S}} / C_{\mathrm{W}}\right) / f_{\mathrm{OC}}
$$

where $C_{\mathrm{S}}(\mathrm{mg} \mathrm{PCBs} / \mathrm{kg}$ sediment) is the concentrations of PCBs in the sediment and $f_{\mathrm{OC}}$ is the mass fraction of the organic carbon in the sediment (based on the measured TOC).

The fugacity of PCBs in sediment and water was calculated as follows [20]:

$$
\begin{aligned}
& f_{\mathrm{S}}=\frac{C_{\mathrm{S}} \times \rho_{\mathrm{S}} \times H}{f_{\mathrm{OC}} \times K_{\mathrm{OW}}} \\
& f_{\mathrm{W}}=C_{\mathrm{W}} \times H
\end{aligned}
$$

where $f_{\mathrm{S}}$ and $f_{\mathrm{W}}$ are the fugacity of PCBs in sediment and water, respectively, and $\rho_{\mathrm{S}}$ is the density of the solid sediment $\left(1.50 \times 10^{3} \mathrm{~kg} / \mathrm{m}^{3}\right.$ for all calculations).

The fraction of the total fugacity (ff) was calculated as [25]

$$
\mathrm{ff}_{\mathrm{SW}}=f_{\mathrm{S}} /\left(f_{\mathrm{S}}+f_{\mathrm{W}}\right)
$$

where $\mathrm{ff}_{\mathrm{SW}}$ represents the fugacity fraction of PCBs in sediment.

The carcinogenic risk and non-carcinogenic risk are calculated as follows [26]:

$$
\begin{aligned}
& \mathrm{CR}=\frac{C_{i} \times \mathrm{IR} \times \mathrm{EF} \times \mathrm{SF}}{\mathrm{BW} \times \mathrm{AT}} \\
& \mathrm{HI}=\frac{C_{i} \times \mathrm{IR} \times \mathrm{EF} \times \mathrm{ED}}{\mathrm{BW} \times \mathrm{AT} \times \mathrm{RfD}}
\end{aligned}
$$

where $C_{i}$ is the concentration of PCBs in water $(\mathrm{mg} / \mathrm{L})$; IR the daily drinking water volume $(1.85 \mathrm{~L})$; EF the adult exposure frequency ( $365 \mathrm{~d} / \mathrm{a})$; SF the carcinogenic slope factor $(2 \mathrm{~kg} \mathrm{~d} / \mathrm{mg})$; BW the body weight of an adult $(60 \mathrm{~kg})$; AT the average time of the onset of carcinogenic effect (25550 d); ED the adult exposure period (70 a); and RfD the exposure dose $(0.02 \mathrm{mg} / \mathrm{d} \mathrm{kg})$. All values were 
taken from the Chinese population exposure parameter manual [27].

\section{Results and discussion}

\section{PCB levels in the water, sediment, and SPM}

Additional file 1: Table S1 lists the total concentrations of PCBs ( $\Sigma$ PCBs) and predominant PCB congeners in the water, sediment, and SPM of the Yangtze River, which range in $0.04-11 \mathrm{ng} / \mathrm{L}, 0.33-69 \mathrm{ng} / \mathrm{g}$, and $0.72-153 \mathrm{ng} / \mathrm{L}$, respectively. The concentrations of ind-PCBs in water, sediment, and SPM are $0.005-0.38 \mathrm{ng} / \mathrm{L}, 0.06-21.5 \mathrm{ng} / \mathrm{g}$, and $0.25-4.04 \mathrm{ng} / \mathrm{L}$, respectively. For the 12 types of coPCBs, their concentration in the three phases ranges in ND-0.23 ng/L, ND-8.41 ng/g, and ND-1.27 ng/L, with a median value of $0.03 \mathrm{ng} / \mathrm{L}, 0.03 \mathrm{ng} / \mathrm{g}$, and $0.23 \mathrm{ng} / \mathrm{L}$, respectively. The $\Sigma$ PCBs level in water is thus comparable to that of the Pearl River Estuary (China) (0.02-14.8 ng/L) [28] and the Houston waterway (up to $12.5 \mathrm{ng} / \mathrm{L}$ ) [29], but significantly lower than that of the Ebro River (up to $108 \mathrm{ng} / \mathrm{L}$ ) [30]. The $\Sigma \mathrm{PCBs}$ level in sediment is comparable to that of the Pearl River Delta surface sediment (3.50-48.3 ng/g) but is at the low end of the global PCBs level $(0.20-400 \mathrm{ng} / \mathrm{g})$ [31]. The $\Sigma$ PCBs level in SPM is higher than that of the Dalian River estuary (6.78-66.6 ng/L) and the Portuguese coast (4.2$30.1 \mathrm{ng} / \mathrm{L}$ ) [32], but much lower than that of the Newark bay estuary (466-966 $\mathrm{ng} / \mathrm{L})$ [33]. It can be seen from the above comparisons with other systems around the globe that the PCBs' pollution at the Yangtze River is at a low to medium level [34]. Generally, the $\Sigma$ PCBs level tends to be higher in water and SPM in the middle reaches than the downstream, but the reverse is true for sediment.

The PCBs concentration is the highest at Y-2, Y-5, Y-7, and Y-9 (all in the vicinity of Wuhan) for SPM and at Y-25 and Y-28 (both in the Jiangsu province) for sediment, respectively. Point sources are likely involved in these localized high PCBs' level. Besides, various other factors including hydrodynamics, crystal size, etc., may also drive up the PCBs concentration [35]. In fact, Y-25 is in the tributary of the Yangtze River, where sediment particle size and low hydrodynamics may contribute to high PCBs.

\section{Characteristics of PCBs in the water, sediment, and SPM}

Figures 2, 3, and 4 present the distribution PCB homologues in water, sediment, and SPM. In water, di-CBs and tetra-CBs are the dominant congeners $(>40 \%$ of the total) in the middle reaches, whereas di-CBs and penta$\mathrm{CBs}$ are the dominant congeners in the lower reaches near Jiangsu (Fig. 2). The findings are consistent with the results of Zhang et al. [19], in which tetra-CBs were found to be the predominant contaminants. The PCBs in

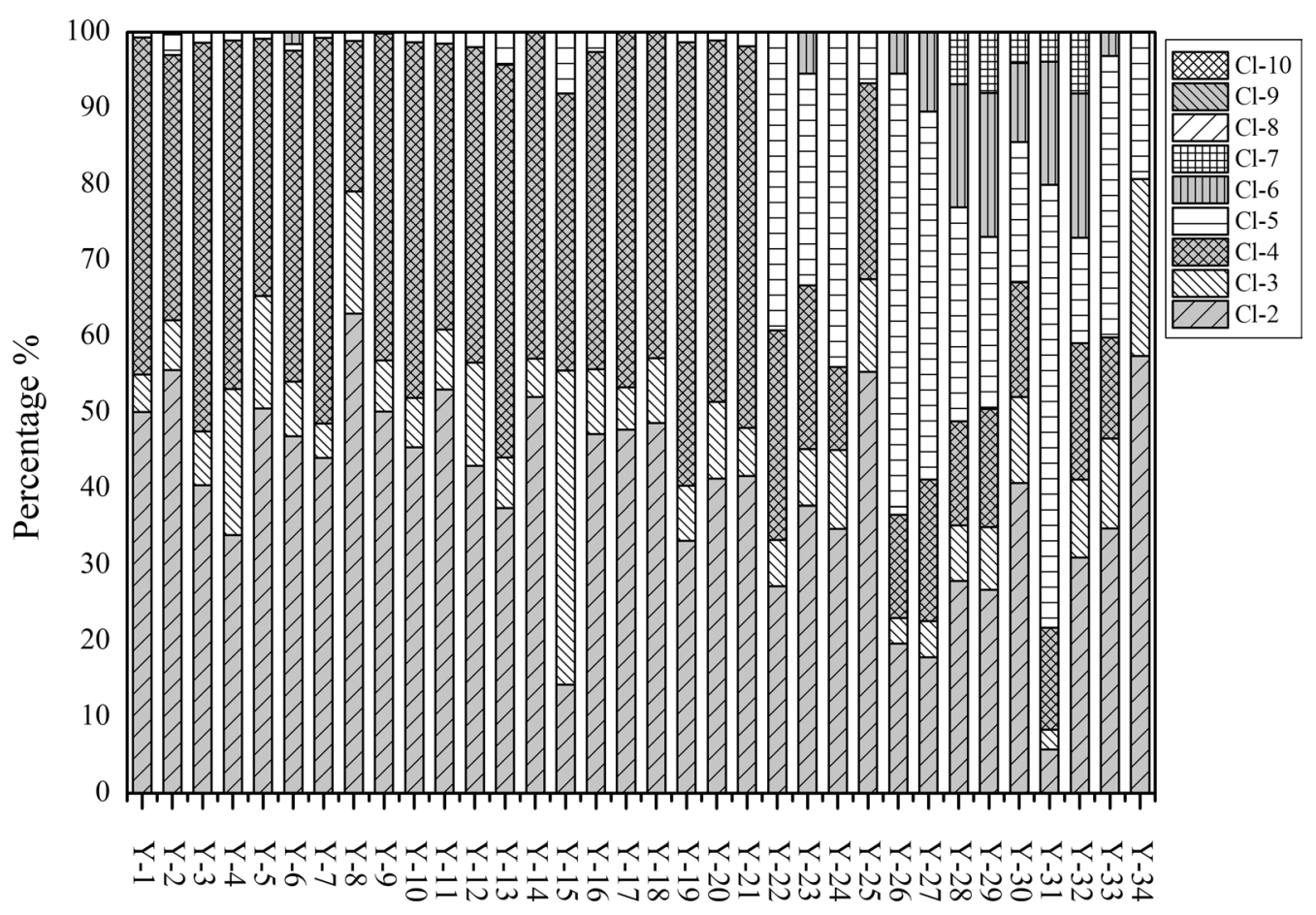

Water sampling sites

Fig. 2 The percentage of PCB homologues in the water of the Yangtze River 


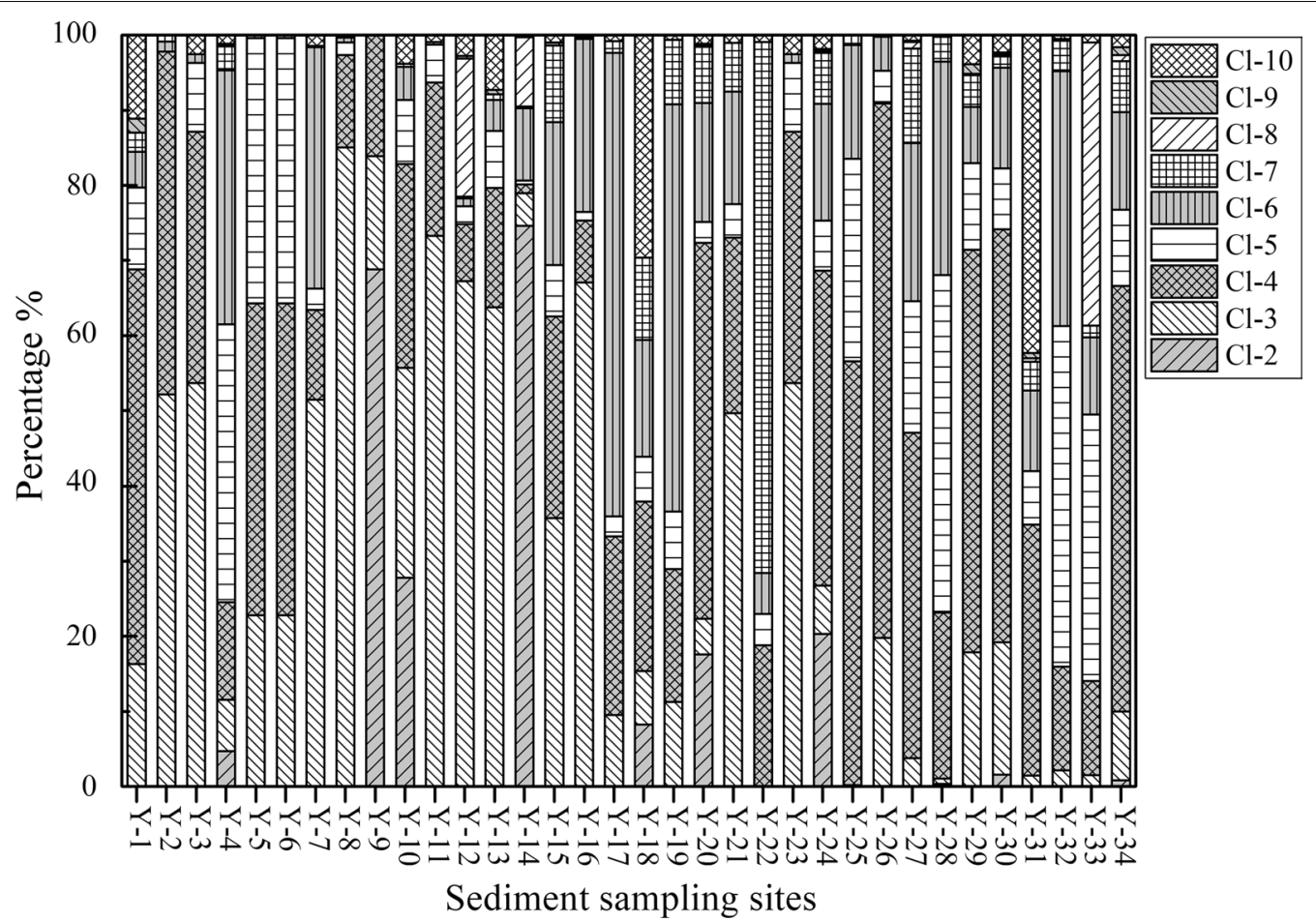

Fig. 3 The percentage of PCB homologues in the sediment of the Yangtze River

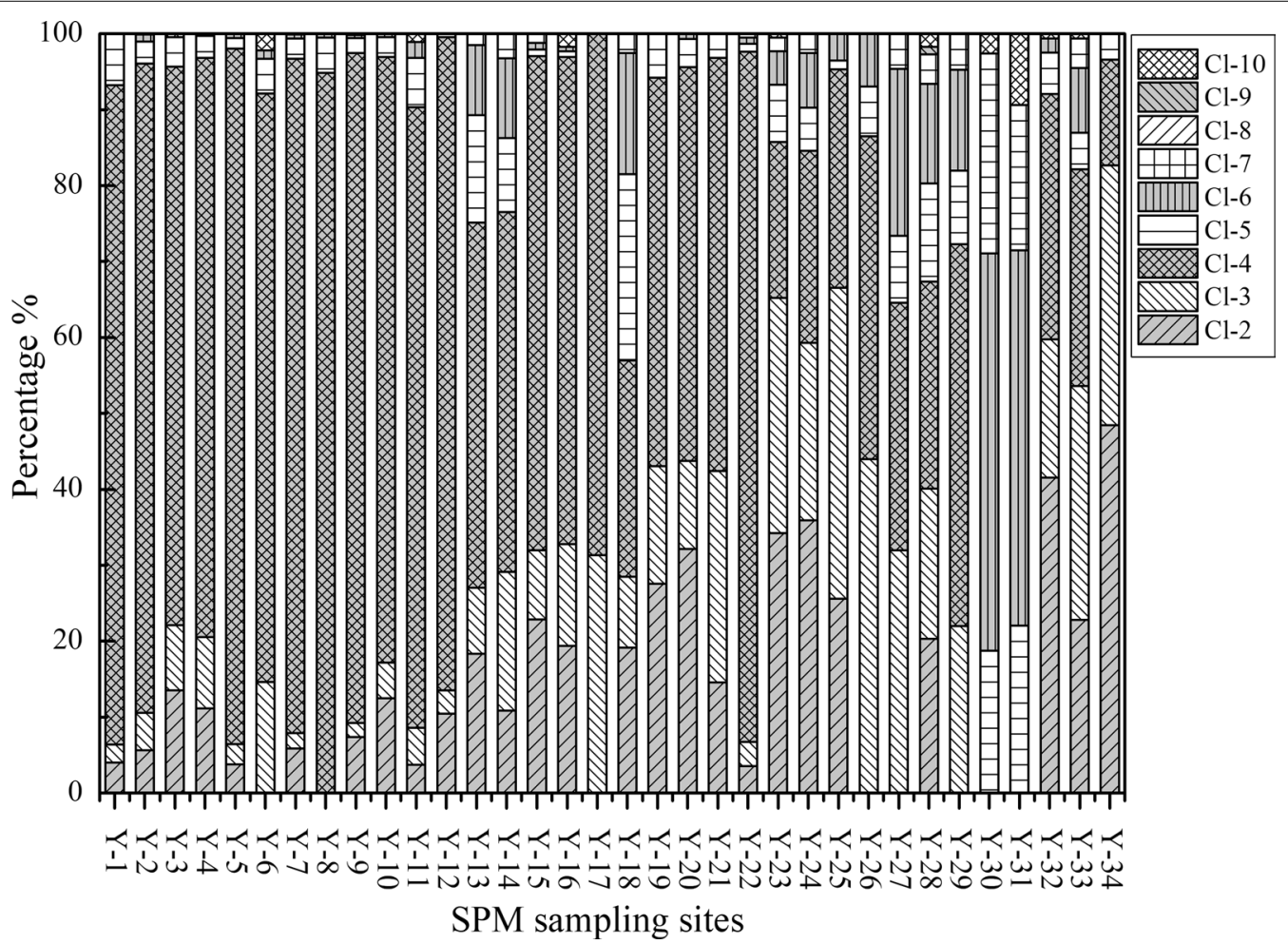

Fig. 4 The percentage of PCB homologues in the SPM of the Yangtze River 
the sediment are mainly tri-CBs and tetra-CBs, and the proportion of penta-CBs and hexa-CBs increases in the downstream (Fig. 3). The PCBs' distribution in the sediment of the Yangtze River resembles that of the coastal East China Sea [18]. The PCBs in the SPM are mainly tetra-CBs (>70\%), although the proportion of di-CBs and tri-CBs increases in the downstream section (Fig. 4).

In general, for both water and sediment, lower chlorinated biphenyls are the dominant congeners in the middle reaches and higher chlorinated biphenyls are the dominant congeners in the lower reaches. Tetra-CBs are the dominant congeners in SPM.

Two representative types of PCBs (ind-PCBs and coPCBs) were analyzed as the indicators of environmental pollution and toxicity [9]. The proportion of seven indPCBs to $\Sigma$ PCBs varied between 1.54 and $64.4 \%$. The congener profile of the ind-PCBs is dominated by the tri-CB PCB28 and the penta-CB PCB118, and other congeners contribute much less. Besides, the concentration of coPCBs is significantly lower in water than in SPM, likely due to the low polarity, poor water solubility, and low content of co-PCBs in water.

The fingerprint of the detected PCBs differs in the three phases. PCB11 is detected in all water samples. PCBs 47 and 41 are detected more frequently in SPM and in sediment than in water, whereas PCB 138 is detected more frequently in sediment than in water and in SPM. In contrast, Zhang et al. [19] found for the Yangtze River that the most abundant congeners are PCB28, 18, 66, 44, and 52 in water and PCB 138, 153, 156, 194, and 209 in SPM. The main component of SPM in this study was low chlorinated PCBs, while that of SPM in Zhang et al. mainly was high chloride PCBs.

Principal component analysis (PCA) was carried out for PCBs that were detected with $>55 \%$ frequency and representative in the three phases, including PCB11, 17, $18,28,41,47,51,66,70,74,110,118,138,153$, and 209. In the PCA results (Figs. 5 and 6), PC1 accounts for $69.3 \%$ of the variation, and its representative congeners include PCB47, 41, 51, 11, 18, 17, 66, and 28. The PC2 accounts for $14.8 \%$ of the variation, and its representative congeners include PCB70, 110, 138, 118, 153, and 74. PC1 has higher loading for the lower chlorinated homologues like tri- and tetra-CBs, whereas PC2 has higher loading for the higher chlorinated homologues like penta- and hexaCBs (Fig. 5). The PCA results also indicate that at sites 25 and 28, the sediment is affected by PCB138, 110, and 70 (Fig. 6), water is mainly affected by PCB11, and the SPM is affected by PCB47, 41, and 51. This is also consistent with the results of [36], where higher PCBs are more readily adsorbed by natural organic matter (NOM) with time.

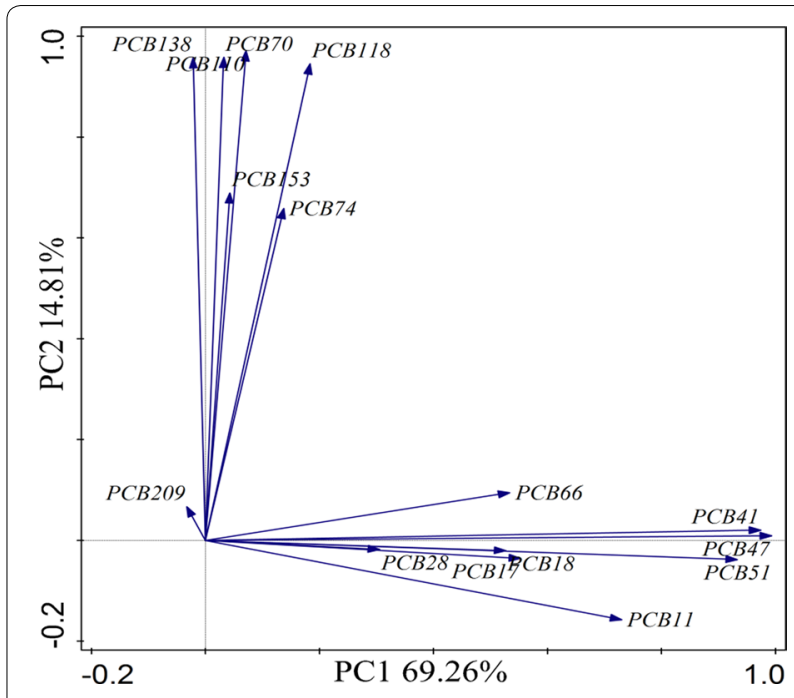

Fig. 5 Principal component profile of PCBs in the water, sediment, and SPM of the Yangtze River

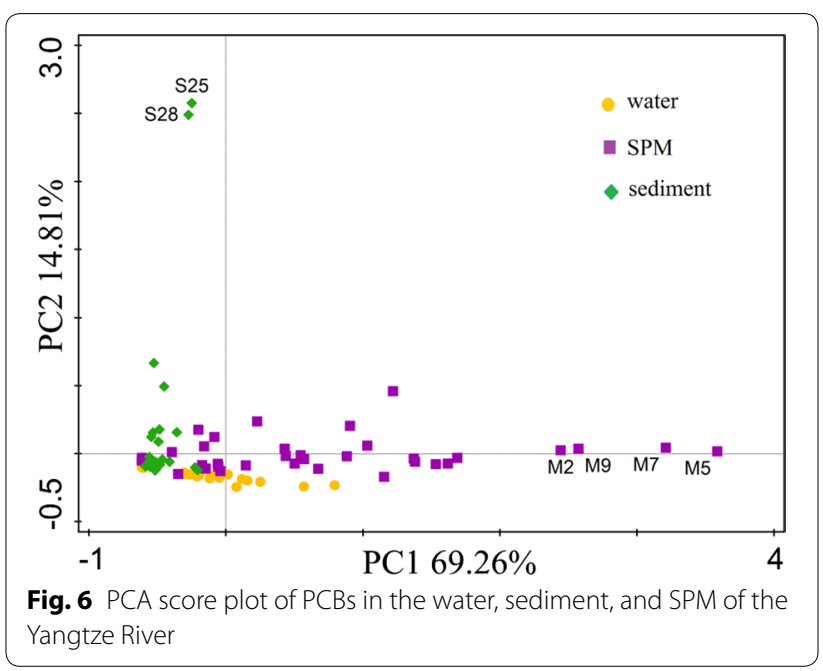

Transport of PCBs among multi-matrix compartments The exchange of pollutants among multi-matrix compartments is a very complicated process that involves many factors including van der Waals forces, particle size, covalent bonds, temperature, etc. Multiple parameters are used to represent the transport of pollutants between media [36].

In this study, predominant $\mathrm{PCB}$ congeners in water, sediment, and SPM (including PCB18, 28, 47, and 118) were selected to evaluate the transport of PCBs among multi-matrix compartments. The SPM-water partition coefficient $\left(K_{\mathrm{d}}\right)$ reflects whether the adsorption of chemical substances favors the SPM than the aqueous environment. The $\log K_{\mathrm{d}}$ values of PCB18, 28, 47, and 
118 were calculated from Eq. (1) to be 3.50-4.16, 3.20$4.28,3.17-4.90$, and 3.03-4.07, respectively. Hence, the four PCBs have similar $K_{\mathrm{d}}$. Organic matter content, temperature, mineral composition, and median particle size are all important factors affecting $K_{\mathrm{d}}$ value.

The diffusion of dissolved contaminant from sediment to water is one of the main transport processes. The $K_{\mathrm{OC}}$ value is compared with $K_{\mathrm{OC}}{ }^{*}$ to predict whether PCBs have reached equilibrium between sediment and water in the field [25]. The $\log K_{\mathrm{OC}}{ }^{*}$ values of PCB18, PCB28, PCB47, and PCB118 range in 2.99$4.90,3.00-4.20,2.97-4.71$, and 2.91-4.18, respectively, all much less than the predicted equilibrium $\log K_{\mathrm{OC}}$ value $(5.16,5.18,5.87$, and 6.19 , respectively). That is, the transport of PCB18, PCB28, PCB47, and PCB118 in sediment and water did not reach equilibrium yet. Thus, just like organochlorine pesticides (OCPs), known as persistent organic pollutants, $\mathrm{PCBs}$ have not reached equilibrium in their exchange between sediment and water either [36].

The fugacity fraction is commonly used to demonstrate the equilibrium state because the two directions of the equilibrium line $(\mathrm{ff}=0.50)$ represent the same level of the deviation from the balanced state. The value of the fugacity fraction (ff) can be used as one of the indicators to evaluate the transport of PCBs between two phases. Specifically, transport occurs from sediment to water when $\mathrm{ff}_{\mathrm{SW}}>0.50$ and in the reverse when $\mathrm{ff}_{\mathrm{SW}}<0.50$.

The $\mathrm{ff}_{\mathrm{SW}}$ values (Table 1) indicate that PCB18 and 28 have net redissolution from sediment to water, except for that PCB18 at Y-5. In contrast, PCB47 and PCB118 in most cases (except for $\mathrm{PCB} 118$ at $\mathrm{Y}-4$ ) have $\mathrm{ff}_{\mathrm{SM}}$ $<0.50$, corresponding to net sorption from water to sediment. As the number of chlorine atoms increases,

Table 1 The $\mathrm{ff}_{\text {SW }}$ values of PCB18, 28, 47, and 118 in the Yangtze River

\begin{tabular}{lllll}
\hline Sampling site & $\mathbf{f f}_{\text {Sw }}$ & & & \\
\cline { 2 - 5 } & PCB18 & PCB28 & PCB47 & PCB118 \\
\hline Y-3 & 0.83 & 0.94 & 0.06 & 0.19 \\
Y-4 & 0.73 & 0.77 & 0.05 & 0.90 \\
Y-5 & 0.33 & 0.70 & 0.01 & 0.05 \\
Y-7 & 0.79 & 0.96 & 0.01 & 0.15 \\
Y-12 & 0.79 & 0.98 & 0.04 & 0.09 \\
Y-13 & 0.92 & 0.98 & 0.06 & 0.10 \\
Y-15 & 0.81 & 0.94 & 0.27 & 0.06 \\
Y-16 & 0.99 & 0.99 & 0.29 & 0.39 \\
Y-19 & 0.80 & 0.89 & 0.03 & 0.14 \\
Y-20 & 0.70 & 0.60 & 0.11 & 0.17 \\
\hline
\end{tabular}

PCBs tend to reach saturation in water and show migration from water to sediments. PCBs are different from OCPs according to Jin and Liu et al., whose $\mathrm{ff}_{\mathrm{SW}}$ values show net sorption from water to sediment $[27,36]$.

A fugacity fraction in $0.20-0.80$ may not represent a significant deviation from equilibrium, and there are other parameters that are difficult to include in the error. The sediment-water model provides a preliminary basis to describe the transport of pollutants in two media and needs to be further verified.

\section{Ecotoxicological and health risk assessment}

PCBs in sediment have certain effects on the environment, and benthic organisms are also affected by sediment-bound PCBs [37]. We use the sediment quality guidelines (SQG) to assess the potential ecotoxicological impacts of organic contaminants in the surface sediment of the Yangtze River. Specifically, the rangelow (ER-L) and range-median (ER-M) values refer to the lower 10 percentile and median values, respectively [38]. In this study, the $\Sigma$ PCBs concentration (Additional file 1: Table S2) is below the ER-L (22.7 $\mathrm{ng} / \mathrm{g})$ except at Y-25 and Y-28, and neither $(69.4 \mathrm{ng} / \mathrm{g}$ for $\mathrm{Y}-25$ and $59.4 \mathrm{ng} / \mathrm{g}$ for $\mathrm{Y}-28)$ is greater than the ER-M $(180 \mathrm{ng} / \mathrm{g})$. Because the $\Sigma \mathrm{PCBs}$ level is much lower than ER-L, the ecological risk of PCBs in the sediments is deemed reasonably low, but the PCBs pose potential ecological risk in $5.9 \%$ of the sampling sites.

According to the Canadian soil quality guidelines, the standard value of polychlorinated dibenzo- $p$-dioxins/ dibenzofurans (PCDD/Fs) is $4.0 \mathrm{pg} / \mathrm{g}$ [39]. In this study, the TEQ of PCBs in sediment falls in ND-2.51 pg$\mathrm{TEQ} / \mathrm{g}$, with a median value of $0.0007 \mathrm{pg}-\mathrm{TEQ} / \mathrm{g}$. Therefore, the sediment has a low ecotoxicological risk.

The TEQ of co-PCBs in water ranges from ND to $5.55 \mathrm{pg}-\mathrm{TEQ} / \mathrm{L}$. The TEQ is lower than the environmental quality standard (1.00 pg-TEQ/L) set by the Japanese government [15] at sites other than Y-26, Y-27, Y-28, Y-29, and Y-30. The sites in the Jiangsu province have higher TEQ of PCBs in water, and thus the ecotoxicological risk in the lower reaches of the Yangtze River.

The carcinogenic and non-carcinogenic health risk assessment models were also applied [40]. The carcinogenic and non-carcinogenic risk of PCBs in water varies from $3.87 \times 10^{-11}$ to $9.67 \times 10^{-9}$ and from $6.78 \times 10^{-8}$ to $1.69 \times 10^{-5}$, respectively. The carcinogenic risk of PCBs is much less than the risk threshold $\left(1 \times 10^{-6}\right)$ defined by the US EPA and thus negligible. Because the PCBs are harmful to humans when the non-carcinogenic risk exceeds 1 , the PCBs in water do not show a non-carcinogenic risk either. 


\section{Conclusions}

In this study, the PCBs of water, sediment, and suspended particulate matter (SPM) in the drinking water source of the Yangtze River were determined with isotope dilution HRGC/HRMS. The $\Sigma$ PCBs concentration ranges in $0.04-11 \mathrm{ng} / \mathrm{L}, 0.33-69 \mathrm{ng} / \mathrm{g}$, and $0.72-153 \mathrm{ng} / \mathrm{L}$ in water, sediment, and SPM, respectively. Compared with other regions, the Yangtze River has a low to medium level of PCBs pollution.

In general, for both water and sediment, lower chlorinated biphenyls are the dominant congeners in the middle reaches, and higher chlorinated biphenyls dominate in the lower reaches. Among all congeners, PCB11, 17, 18, 28, and 118 have higher detection frequency in water, sediment, and SPM. The distribution of PCBs varies across the three phases. The SPM mainly contains PCB47, 41, and 51, whereas the sediment mainly contains PCB138, 110, and 70 .

The value of $\mathrm{ff}_{S M}$ indicates that the diffusion of PCB18, 28, 47, and 118 in sediment and water is away from equilibrium. The results show that PCB18 and 28 have net redissolution from sediment to water, while PCB47 and PCB118 have net sorption from water to sediment. Risk assessment results indicate potential ecological risk from PCBs in the water and sediment of the Yangtze River, but neither carcinogenic nor noncarcinogenic risk was found from the PCBs.

\section{Supplementary information}

Supplementary information accompanies this paper at https://doi. org/10.1186/s12302-020-00309-6.

Additional file 1: Table S1. The concentrations of PCB congeners in water (pg/L), SPM (pg/L), and sediment (pg/g) of the Yangtze River. Table S2. The TEQ of Co-PCBs in sediment in sediment and water and the carcinogenic and non-carcinogenic risk of PCBs in water.

\begin{abstract}
Abbreviations
PCBs: Polychlorinated biphenyls; SPM: Particulate matter; TEQ: Toxic equivalent quantity; ind-PCBs: Indicative polychlorinated biphenyls; Co-PCBs: Coplanar polychlorinated biphenyls; QC: Quality control; QA: Quality assurance; RSD: Relative standard deviation; PCA: Principal component analysis; NOM: Natural organic matter; OCPs: Organochlorine pesticides; SQG: Sediment quality guidelines; ER-L: Range-low; ER-M: Range-median; PCDD/Fs: Polychlorinated dibenzo-p-dioxins/dibenzofurans.
\end{abstract}

\section{Acknowledgements}

None applicable.

\section{Authors' contributions}

$X Z, X C$, and JD were involved in the experiments and manuscript writing. $Z H$ was responsible for the data analysis. $C L, X Q$, and $X W$ collected the samples. $\mathrm{BZ}$ and JS contributed to correction of the manuscript. All authors read and approved the final manuscript.

\section{Funding}

This work was supported by the Water Pollution Control and Management (No. 2018ZX07502-001-005).

\section{Availability of data and materials}

The datasets obtained and analyzed in the current study are available from the corresponding author on reasonable request.

\section{Ethics approval and consent to participate}

Not applicable.

\section{Consent for publication}

Not applicable.

\section{Competing interests}

The authors declare that they have no competing interests.

\section{Author details}

${ }^{1}$ National Engineering Laboratory for Lake Pollution Control and Ecological Restoration, State Environmental Protection Key Laboratory of Drinking Water Source Protection, Chinese Research Academy of Environmental Sciences, Beijing 100012, China. ${ }^{2}$ Hebei Normal University, Shijiazhuang 050024, China.

Received: 23 December 2019 Accepted: 14 February 2020

Published online: 26 February 2020

References

1. Yang Z, Wang H, Saito Y, Milliman J, Xu K, Qiao S, Shi G (2006) Dam impacts on the Changjiang (Yangtze) River sediment discharge to the sea: the past 55 years and after the Three Gorges Dam. Water Resour Res 42(4):W04407

2. Chen J, Wu X, Finlayson B, Webber M, Wei T, Li M, Chen Z (2014) Variability and trend in the hydrology of the Yangtze River, China: annual precipitation and runoff. J Hydrol 513:403-412

3. Wang Z, Chen Q, Zhang J, Dong J, Yan H, Chen C, Feng R (2019) Characterization and source identification of tetracycline antibiotics in the drinking water sources of the lower Yangtze River. J Environ Manage 244:13-22

4. Wang Z, Shao D, Westerhoff P (2017) Wastewater discharge impact on drinking water sources along the Yangtze River (China). Sci Total Environ 599-600:1399-1407

5. Shang X, Dong G, Zhang H, Zhang L, Yu X, Li J, Wang X, Yue B, Zhao Y, Wu $Y$ (2016) Polybrominated diphenyl ethers (PBDEs) and indicator polychlorinated biphenyls (PCBs) in various marine fish from Zhoushan fishery, China. Food Control 67:240-246

6. Habibullah-Al-Mamun M, Kawser M, Saiful M, Tokumura M, Masunaga S (2019) Occurrence, distribution and possible sources of polychlorinated biphenyls (PCBs) in the surface water from the Bay of Bengal coast of Bangladesh. Ecotox Environ Safe 167:450-458

7. Hites R (2004) Polybrominated diphenyl ethers in the environment and in people: a meta-analysis of concentrations. Environ Sci Technol 38:945-956

8. Xing Y, Lu Y, Dawson R, Shi Y, Zhang H, Wang T (2005) A spatial temporal assessment of pollution from PCBs in China. Chemosphere 60:731-739

9. Ferrari P, Carletti A, Curtui V, Cappé S, Fabiansson S (2010) Results of the monitoring of dioxin levels in food and feed. EFSA J 8:1385

10. Fliedner $A$, Rüdel $H$, Jürling $H$, Müller J, Neugebauer $F$, Schröter-Kermani C (2012) Levels and trends of industrial chemicals (PCBs, PFCs, PBDEs) in archived herring gull eggs from German coastal regions. Environ Sci Eur 24(1):7

11. Ge F, Wang X, Zhang K, Jin X, Guo R, Liu Y, Zheng X (2019) The correlation study between PCBs and $\delta 15 \mathrm{~N}$ values or FAs in fish collected from Dongting Lake. Chemosphere 234:763-768

12. Gouin T, Mackay D, Jones K, Harner T, Meijer S (2004) Evidence for the "grasshopper" effect and fractionation during long-range atmospheric transport of organic contaminants. Environ Pollut 128:139-148

13. Sahu S, Ajmal P, Pandit G, Puranik V (2009) Vertical distribution of polychlorinated biphenyl congeners in sediment core from thane creek area of Mumbai, India. Hazard Mater 164:1573-1579

14. Apell J, Gschwend P (2016) In situ passive sampling of sediment in the lower Duwamish Waterway Superfund site: replicability, comparison with ex situ measurements, and use of data. Environ Pollut 218:95-101 
15. Zhou S, Yang H, Zhang A, Li Y, Liu W (2014) Distribution of organochlorine pesticides in sediment from Yangtze River Estuary and the adjacent East China Sea: implication of transport, sources and trends. Chemosphere 114:26-34

16. Batang Z, Alikunhi N, Gochfeld M, Burger J, Al-Jahdali R, Al-Jahdali H, Aziz M, Al-Jebreen D, Al-Suwailem A (2016) Congener-specific levels and patterns of polychlorinated biphenyls in edible fish tissue from the central Red Sea coast of Saudi Arabia. Sci Total Environ 572:915-925

17. Wang J, Chen S, Tian M, Zheng X, Gonzales L, Ohura T, Mai B, Simonich S (2012) Inhalation cancer risk associated with exposure to complex polycyclic aromatic hydrocarbon mixtures in an electronic waste and urban area in South China. Environ Sci Technol 46:9745-9752

18. Duan X, Li Y, Li X, Li M, Zhang D (2013) Distributions and sources of polychlorinated biphenyls in the coastal East China Sea sediments. Sci Total Environ 463-464:894-903

19. Zhang L, Shi S, Dong L, Zhang T, Zhou L, Huang Y (2011) Concentrations and possible sources of polychlorinated biphenyls in the surface water of the Yangtze River Delta, China. Chemosphere 85:399-405

20. Zhao T, Guo Z, Yao P, Hu L, Wu Z, Lin T (2019) Deposition flux and mass inventory of polychlorinated biphenyls in sediments of the Yangtze River Estuary and inner shelf, East China Sea: implications for contributions of large-river input and e-waste dismantling. Sci Total Environ 647:1222-1229

21. Zhao X, Cui T, Guo R, Liu Y, Wang X, An Y, Qiao X, Zheng B (2019) A cleanup method for determination of multi-classes of persistent organic pollutants in sediment and biota samples with an aliquot sample. Anal Chim Acta 1047:71-80

22. Benoit P, Madrigal I, Preston C, Chenu C, Barriuso E (2008) Sorption and desorption of non-ionic herbicides onto particulate organic matter from surface soils under different land uses. Eur J Soil Sci 59:178-189

23. Seth R, Mackay D, Muncke J (1999) Estimating the organic carbon partition coefficient and its variability for hydrophobic chemicals. Environ Sci Technol 33:2390-2394

24. Huang H, Zhang Y, Chen W, Chen W, Qi S (2018) Sources and transformation pathways for dichlorodiphenyltrichloroethane (DDT) and metabolites in soils from Northwest Fujian. China Environ Pollut 235:560-570

25. Wang D, Alaee M, Byer J, Liu Y, Tian C (2011) Fugacity approach to evaluate the sediment-water diffusion of polycyclic aromatic hydrocarbons. Environ Monit 13:1589-159642

26. U.S. EPA (U.S. Environmental Protection Agency) 2005. Guidelines for carcinogen risk assessment. Accessed September 2013)

27. Jin X, Liu Y, Qiao X, Guo R, Liu C, Wang X, Zhao X (2019) Risk assessment of organochlorine pesticides in drinking water source of the Yangtze River. Ecotoxicol Environ Saf 182:109390

28. Chen M, Yu M, Luo X, Chen S, Mai B (2011) The factors controlling the partitioning of polybrominated diphenyl ethers and polychlorinated biphenyls in the water-column of the Pearl River estuary in south China. Mar Pollut Bull 62:29-35
29. Howell N, Suarez M, Rifai H, Koenig L (2008) Concentrations of polychlorinated biphenyls (PCBs) in water, sediment, and aquatic biota in the Houston Ship Channel, Texas. Chemosphere 70:593-606

30. Fernández M, Alonso C, González M, Hernández L (1998) Occurrence of organochlorine insecticides, PCBs and PCB congeners in waters and sediment of the Ebro River (Spain). Chemosphere 38:33-43

31. Mai B, Zeng E, Luo X, Yang Q, Zhang G, Li X, Sheng G, Fu J (2005) Abundances, depositional fluxes, and homologue patterns of polychlorinated biphenyls in dated sediment cores from the Pearl River Delta, China. Environ Sci Technol 39:49-56

32. Ferreira A, Martins M, Vale C (2003) Influence of diffuse sources on levels and distribution of polychlorinated biphenyls in the Guadiana River estuary. Port Mar Chem 83:175-184

33. Dimou K, Su T, Hires R (2004) Distribution of polychlorinated biphenyls in the Newark Bay Estuary. J Hazard Mater 136:103-110

34. Zhang S, Zhang Q, Darisaw S, Ehie O, Wang G (2007) Simultaneous quantification of polycyclic aromatic hydrocarbons (PAHs), polychlorinated biphenyls (PCBs), and pharmaceuticals and personal care products (PPCPs) in Mississippi river water, in New Orleans, Louisiana, USA. Chemosphere 66:1057-1069

35. Gao J, Shi H, Dai Z, Mei X, Zong H, Yang H, Li S (2018) Linkages between the spatial toxicity of sediments and sediment dynamics in the Yangtze River Estuary and neighboring East China Sea. Environ Pollut 233:1138-1146

36. Liu J, Qi S, Yao J, Yang D, Xing X, Liu H, Qu C (2016) Contamination characteristics of organochlorine pesticides in multimatrix sampling of the Hanjiang River Basin, southeast China. Chemosphere 163:35-43

37. Weber R, Herold C, Hollert H, Kamphues J, Blepp M, Ballschmiter K (2018) Reviewing the relevance of dioxin and PCB sources for food from animal origin and the need for their inventory, control and management. Environ Sci Eur 30(1):42

38. Wurl O, Obbard J (2005) Organochlorine pesticides, polychlorinated biphenyls and polybrominated diphenyl ethers in Singapore's coastal marine sediments. Chemosphere 58:925-933

39. Wang W, Bai J, Zhang G, Jia J, Wang X, Liu X, Cui B (2019) Occurrence, sources and ecotoxicological risks of polychlorinated biphenyls (PCBs) in sediment cores from urban, rural and reclamation-affected rivers of the Pearl River Delta, China. Chemosphere 218:359-367

40. Wang D, Wang Y, Singh V, Zhu J, Jiang L, Zeng D, Zeng C (2018) Ecological and health risk assessment of PAHs, OCPs, and PCBs in Taihu Lake basin. Ecol Indic 92:171-180

\section{Publisher's Note}

Springer Nature remains neutral with regard to jurisdictional claims in published maps and institutional affiliations.

\section{Submit your manuscript to a SpringerOpen ${ }^{\circ}$ journal and benefit from:}

- Convenient online submission

- Rigorous peer review

- Open access: articles freely available online

- High visibility within the field

Retaining the copyright to your article

Submit your next manuscript at springeropen.com 